\title{
Screening For Very Long Chain Fatty Acids in Egyptian Children with Inherited Peroxisomal Disorders
}

\author{
Ekram M. Fateen $^{1 *}$, Nadia M. Abdallah ${ }^{2}$, Magda K. Ezz ${ }^{2}$, Amr S. Gouda $^{1}$, Sahar M. Hassanein ${ }^{3}$ and \\ Randa M. S. Abd El-Salam ${ }^{1}$ \\ ${ }^{I}$ Biochemical Genetics Department, National Research Center, Cairo, Egypt, \\ ${ }^{2}$ Department of Biochemistry, Faculty of Science, Ain Shams University, Cairo, Egypt, \\ ${ }^{3}$ Pediatric Department, Faculty of Medicine, Ain Shams University, Cairo, Egypt
}

\section{ARTICLE INFO}

Article history:

Received 29 June 2015

Accepted 03 August 2015

Keywords:

Very Long Chain Fatty Acids;

Peroxisomal Disorders;

X-Linked Adrenoleukodystrophy;

Phytanic and Pristanic Acids;

Electro Spray Ionization Mass

Spectrometry.

\begin{abstract}
A B S T R A C T
Human peroxisomal disorders results from peroxisomal biogenesis disorders or from deficiency of a single peroxisomal enzyme or transporter. Peroxisomal disorders lead to a neurologic dysfunction of varying extent for most cases. The goal of this work is to establish a rapid procedure for the diagnosis of peroxisomal disorders for the quantification of very long chain fatty acids in plasma in addition to dried blood spot for comparison to evaluate a reliable, rapid method versus the cost. 50 patients clinically suspicious to have peroxisomal disorders and 25 normal controls were included in this study. Their ages ranged from 2 to 10 years. The patients include $45(90 \%)$ males and $5(10 \%)$ females. Positive consanguinity was present in $32(64 \%)$ cases. Alanine aminotransferase and L- $\gamma$-Glutamyl transferase were measured for all patients to be sure that they are suffering from liver dysfunction. Very long chain fatty acids quantification in plasma and dried blood spots samples using labeled internal standard was done. The same analysis for the plasma samples was repeated using external unlabeled standards. Phytanic and pristanic acids were quantified. The results for alanine aminotransferase and L- $\gamma$-glutamyl transferase revealed their elevation in all patients compared to controls. The plasma and blood spot analysis using labeled internal standards showed that 6 patients (12\%) from 50 had high C24:0, C26:0, C24:0/C22:0 and C26:0/C22:0, which prove the X- linked Adrenoleukodystrophy disorder. The plasma analysis without labeled internal standard showed that the same 6 patients had high C24:0, C26:0, C24:0/C22:0 and C26:0/C22:0, but the results were lower than those of the labeled internal standards except C24:0/C22:0 which was slightly higher. The phytanic acid and pristanic acid results showed a non-significant change. In conclusion, although using Electrospray Ionization Tandem Mass Spectrometry instrument with deuterated internal standards for the determination of very long chain fatty acids is an effective, precise, reliable and rapid screening procedure for many peroxisomal disorders in plasma samples and dried blood spots, using dried blood spots decrease the expensive collection and shipping of plasma samples. Measuring very long chain fatty acids without labeled internal standards decreased the cost, but it is not recommended due to absence of concentration correction effect of the labeled internal standards. In addition, using High Performance Liquid Chromatography with Electrospray Ionization Tandem Mass Spectrometry instrument for measuring phytanic and pristanic acids is a sensitive method, but needs double sample volume and more time for refining.
\end{abstract}

\section{Introduction}

Peroxisomes are organelles found in every eukaryotic

* Corresponding author.

E-mail address: efateen@yahoo.com cell except mature erythrocytes. Many enzymes have been discovered in peroxisomes which participate in both anabolic and catabolic functions. The anabolic functions include synthesis of bile acids, docosahexa- 
enoic acid and plasminogen. Catabolic reactions encompass $\alpha$ and $\beta$-oxidation of very long chain fatty acids (VLCFAs) ${ }^{[1]}$. Peroxisomes work in conjunction with mitochondria to shorten the VLCFA by $\beta$ oxidation, which are in turn degraded to completion in mitochondria. The end result is formation of (acetylCoA) units, which are degraded in the Krebs cycle to produce energy (ATP) ${ }^{[2]}$.

Peroxisomal disorders (PDs) are a heterogeneous group of inborn error of metabolism that results in impairment of peroxisome function ${ }^{[3]}$. They are divided into two categories. The $1^{\text {st }}$ category results from peroxisomal biogenesis disorders (PBDs) which can be divided into two subtypes, the $1^{\text {st }}$ subtype is the Zellweger spectrum disorders (ZSDs) which include at least the following three phenotypes [Zellweger syndrome (ZS), neonatal adrenoleucodystrophy (NALD) and infantile Refsume disease (IRD)]. The $2^{\text {nd }}$ subtype is the rhizomelic chondrodysplasia punctate (RCDP) type 1 . The biochemical parameters for this group of diseases present in accumulation of VLCFAs, trihydroxy cholestanoic acid (THCA), dihydroxy cholestanoic acid (DHCA), phytanic and pristanic acids as well as a decrease in the synthesis of plasmalogen and docosahexaenoic acid (DHA) ${ }^{[4]}$. The $2^{\text {nd }}$ category includes the disorders resulted from the deficiency of a single peroxisomal enzyme or transporter (SEDs). In these disorders the peroxisome is intact and functioning. SEDs include disorders of peroxisomal $\beta$-oxidation e.g. (RCDP type 3, X-linked adrenoleukodystrophy (XALD), acyl-CoA oxidase deficiency, D-bifunctional protein deficiency (BPD), 2-methyl acyl CoA racemase deficiency), disorders of fatty acid $\alpha$-oxidation (Refsum disease), disorders of ether-phospholipid biosynthesis (RCDP Type 2) and hyperoxaluria Type ${ }^{[5]}$. All these disorders are inherited autosomal recessive diseases except X-ALD ${ }^{[2]}$.

$\mathrm{X}$ - linked adrenoleukodystrophy (X-ALD) is the most common PD with impaired $\beta$-oxidation of saturated VLCFAs and clinically different than the other single enzyme deficiencies of peroxisomal $\beta$-oxidation. It is characterized by the accumulation of VLCFA in plasma ${ }^{[6]}$. This disorder is due to mutations in the ABCD1 gene responsible for coding the peroxisomal membrane protein (ALDP) involved in the uptake of VLCFA across peroxisomal membranes ${ }^{[7]}$. X-ALD affect males and females, carriers may develop neurologic manifestations resemble adrenomyeloneuropathy (AMN). The onset of symptoms ranges 2.75-10 years with changes in behavior withdrawal or hyper activity behavior ${ }^{[8]}$. The most frequent present X-ALD is the childhood cerebral ALD (CCALD), most often in early school age. The school performance decline by the onset of CCALD. Other symptoms like white matter lesion, deafness, visual loss, seizures, spastic tetraparesis, and congenital decline leading to death within years after the onset of symptoms $[9,10]$.

X-ALD affecting about one in 20,000 males ${ }^{[2]}$. It is estimated that there are about 1,400 people in the United
States with this disorder. In Egyptian study, X-linked recessive disorder was present in 6 families of $25(24 \%)$ families suffering from peroxisomal disorders ${ }^{[11]}$.

There is no standard course of treatment for PDs. Therapies include supplementation of the diet with antioxidant vitamins or limitation of intake of fatty acids, especially VLCFAs. Lorenzo's oil known as a good treatment for decreasing X-ALD symptoms ${ }^{[12]}$. Bone marrow transplantation could help in the early stage of the disease. The treatments with hypolipidemic drug Lovastatin normalize VLCFA in X-ALD patient's plasma and increase in peroxisome, ABCD1 and Pex $11 \alpha$ ${ }^{[13]}$. Recent studies mentioned that the standard effective treatment for cerebral X-ALD is hematopoietic cell therapy (HCT) ${ }^{[14,15]}$.

\section{Subjects and methods}

\section{Subjects}

Plasma and dried blood spots samples were obtained on Guthrie cards from 50 patients clinically suspected to have peroxisomal disorders selected from Ain Shams University Hospital in Egypt, aging from 2 - 10 years, in addition to 25 normal controls (GI), of matching age and sex. Controls have been received from children planning to have surgery in Pediatric Surgery Department. The samples were divided to three groups, GI (25 controls), GIIa (44 patients with peroxisomal disorders other than (X-ALD) and GIIb (6 X-ALD diagnosed patients).

ALT (EC 2.6.1.2) was determined calorimetrically (Randox Kit, U.K.) according to the method of Bergmeyer and Horder ${ }^{[16]}$. $\gamma \mathrm{GT}$ (EC 2.6.1.2) was determined calorimetrically (Randox Kit, U.K.) according to the method of Szasz ${ }^{[17]}$. VLCFAs (eicosanoic acid (C20:0), docosanoic acid (C22:0), tetracosanoic acid (C24:0) and hexacosanoic acid (C26:0) in 5 ul of plasma samples and 3-mm blood spot were measured according to the method of Johnson ${ }^{[18]}$ by ESI-MS/MS using labeled internal standards. The VLCFAs content of adjacent blank 3-mm disks of filter paper were subtracted. All samples were measured again with the same method but without labeled internal standards to decrease the cost. Phytanic and pristanic acids in plasma were determined according to the method of Johnson et. al. ${ }^{[19]}$, using HPLC and ESIMS/MS.

\section{Chemicals}

The deuterated internal standards were prepared on demand by Dr. Herman Ten Brink, VU medical center, Amsterdam, Netherland. The undeuterated standards were purchased from (Sigma-Aldrich), rest of the chemicals purchased from (Sigma-Aldrich and Merck).

\section{Statistical Analysis}

The Statistical Package for the social sciences (SPSS 17.0) computer program was used for statistical analysis of the results. Data were analyzed using student T-test to determine significant differences between means. The data were expressed as range, mean \pm standard deviation (S.D.). Mean difference was considered significant at $\mathrm{P}<$ 0.05 and highly significant at $P<0.01$. Coefficient of 
Variation (C.V.) was calculated for the validation analysis.

\section{Results}

Clinical examination and pedigree construction were done for 50 patients. Positive parental consanguinity was present in 32 cases $(64 \%)$. Their ages ranged between 2 to 10 years and were 45 males $(90 \%)$ and 5 females $(10$ $\%$ ) (Table 1). Forty four patients showed normal profile for VLCFAs (GIIa), while the other six patients (GIIb) with X-ALD were diagnosed according to their abnormal very long chain fatty acid profile.

ALT and $\gamma \mathrm{GT}$ for groups (GI), (GIIa) and (GIIb) samples have been measured. (GIIa) and (GIIb) cases showed a highly significant increase in levels of ALT and $\gamma \mathrm{GT}$ compared to GI. Also (GIIb) showed a highly significant increase in levels of ALT and $\gamma \mathrm{GT}$ compared to GIIa (Table 2).
Quantification of VLCFAs was achieved by adding trideuterated internal standards to the plasma samples and monitoring the neutral loss of $(\mathrm{m} / \mathrm{z} 45)$ product on the ESI/MS/MS instrument from each of the VLCFA and their trideuterated analogues by MRM experiments (Fig. 1). In control group, the deuterated internal standard was detected, and the MRM mode monitor the following ion pairs 412.5 (C22:0), $415.51\left({ }^{2} \mathrm{H}_{3}-\mathrm{C} 22: 0\right), 440.65$ (C24:0), $443.42\left({ }^{2} \mathrm{H}_{3}-\mathrm{C} 24: 0\right)$ and 471.62 (2H3-C26:0), while C26:0 was not detected in the control sample due to its low concentration (Fig. 2). In X-ALD disorder patients, the deuterated internal standard and C26:0 were detected. The MRM mode monitor the following ion pairs 412.5 (C22:0), $415.51 \quad\left({ }^{2} \mathrm{H}_{3}-\mathrm{C} 22: 0\right), \quad 440.65(\mathrm{C} 24: 0), 443.42$ $\left({ }^{2} \mathrm{H}_{3}-\mathrm{C} 24: 0\right), 468.55$ (C26:0) and $471.62\left({ }^{2} \mathrm{H}_{3}-\mathrm{C} 26: 0\right)$ (Fig. 3).

Table 1: Age, sex, and consanguinity of the six X-ALD diagnosed cases.

\begin{tabular}{|c|c|c|c|}
\hline Patient & Age (year) & Sex & Consanguinity \\
\hline 1 & 3.75 & $\sigma^{\lambda}$ & $+\mathrm{ve}$ \\
\hline 2 & 5.5 & 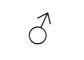 & $+\mathrm{ve}$ \\
\hline 3 & 2.8 & $\hat{0}$ & - ve \\
\hline 4 & 6.7 & $\delta$ & $+\mathrm{ve}$ \\
\hline 5 & 4.2 & $\delta$ & $+\mathrm{ve}$ \\
\hline 6 & 5.1 & 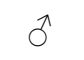 & $+\mathrm{ve}$ \\
\hline
\end{tabular}

Table 2: Serum ALT and $\gamma$ GT mean values for all studied groups.

\begin{tabular}{|c|c|c|}
\hline Groups & ALT U/L & $\gamma$ GT U/L \\
\hline GI & & \\
Range & $20-38$ & $29-49$ \\
Mean \pm S.D. & $28.32 \pm 4.21$ & $37.64 \pm 6.284$ \\
\hline GIIa & & \\
Range & $41-62$ & $51-73$ \\
Mean \pm S.D. & $45.14 \pm 2.61$ & $55.64 \pm 2.40$ \\
P < & 0.001 & 0.001 \\
\hline GIIb: & & $60-73$ \\
Range & $50-62$ & $65.33 \pm 5.16$ \\
Mean \pm S.D. & $56.00 \pm 4.60$ & 0.001 \\
P < & 0.001 & \\
\hline
\end{tabular}




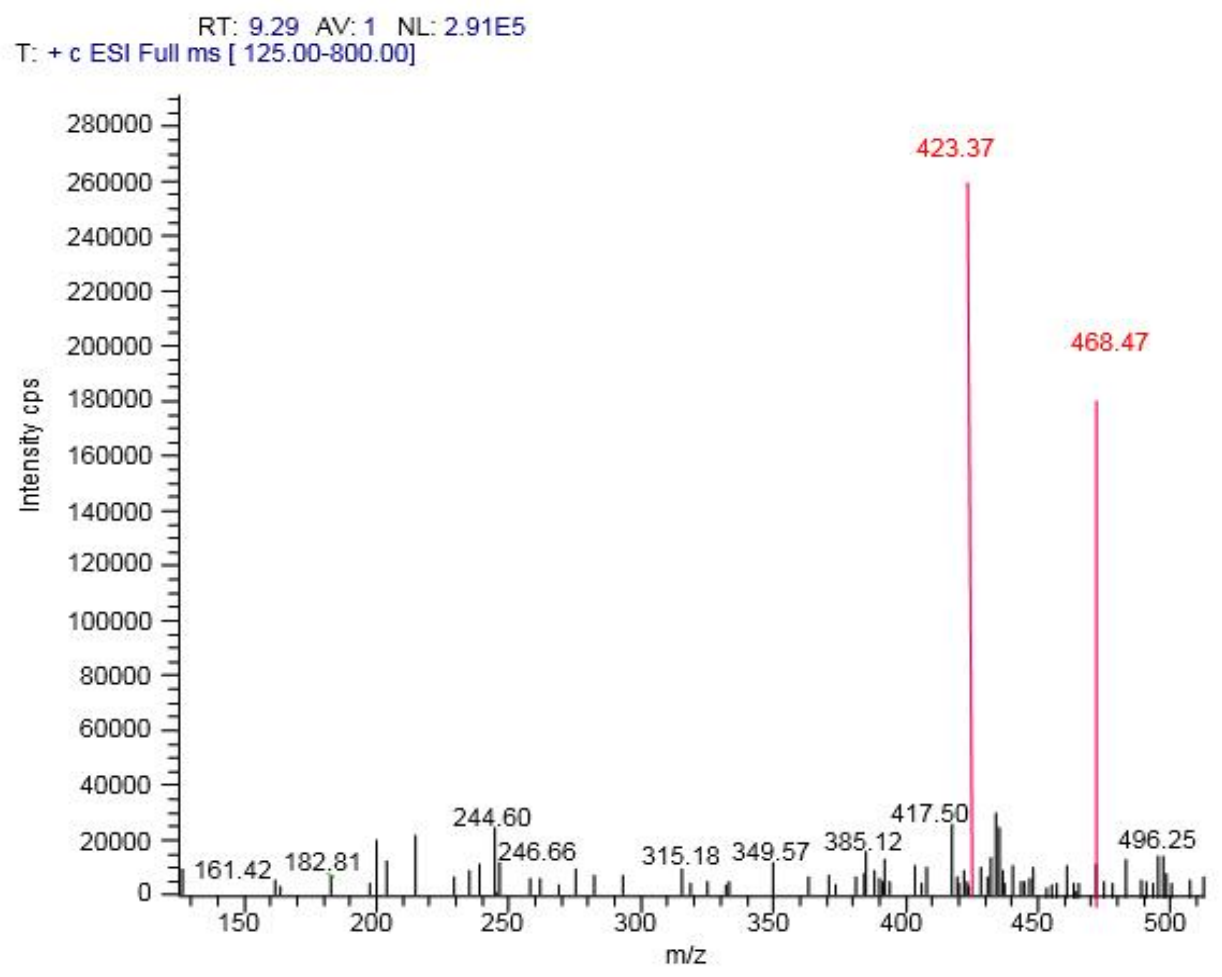

Fig. 1: Product ion scans of the protonated molecular ion $(\mathrm{m} / \mathrm{z} 468)$ of the dimethylaminoethyl ester of hexacosanoic acid (C26:0).

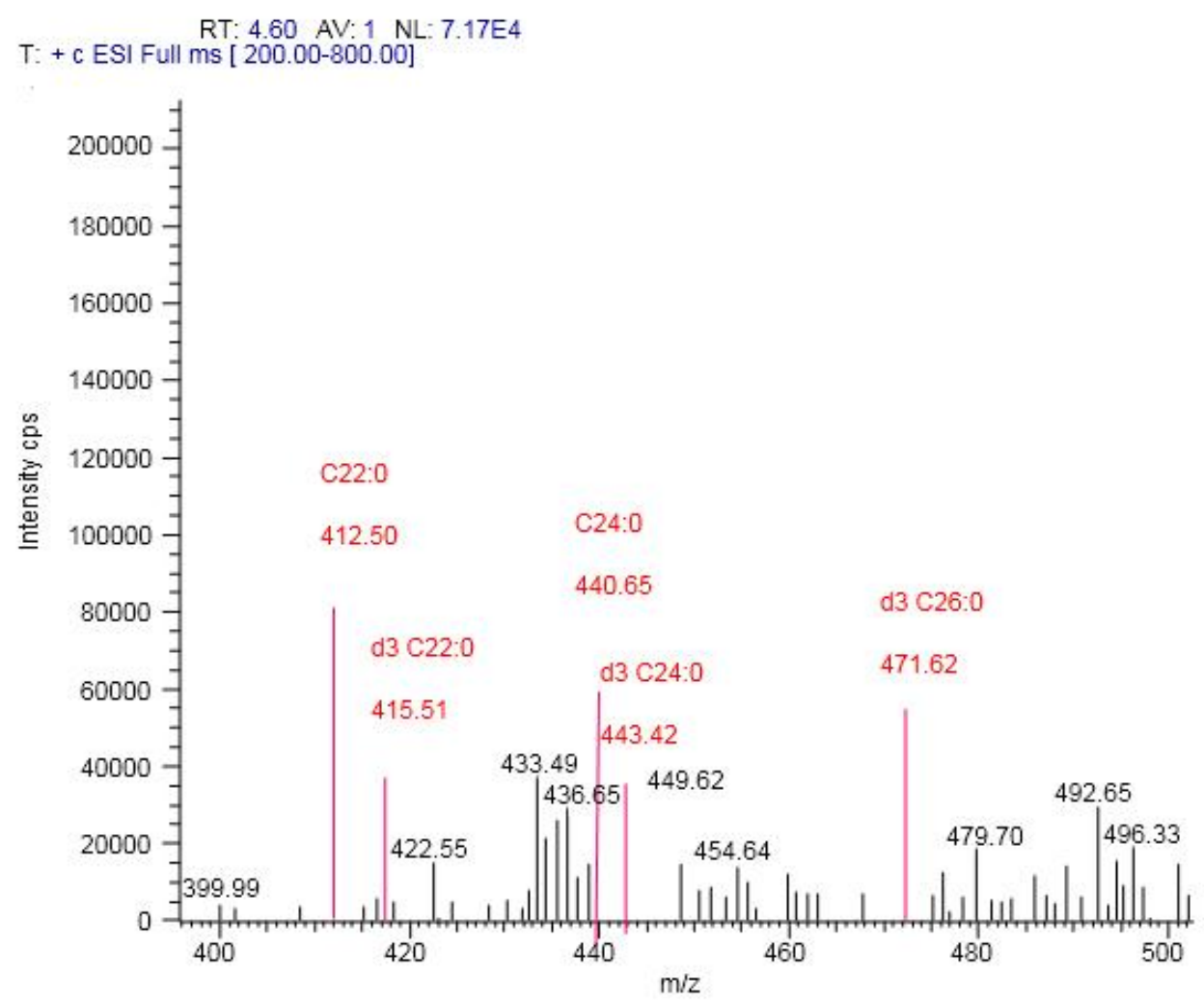

Fig. 2: ESI-MS/MS of the dimethylaminoethyl esters of fatty acids isolated from $5 \mu$ l plasma sample of the control group with deuterated internal standards (d3 C22:0, d3 C24:0 \& d3 C26). 


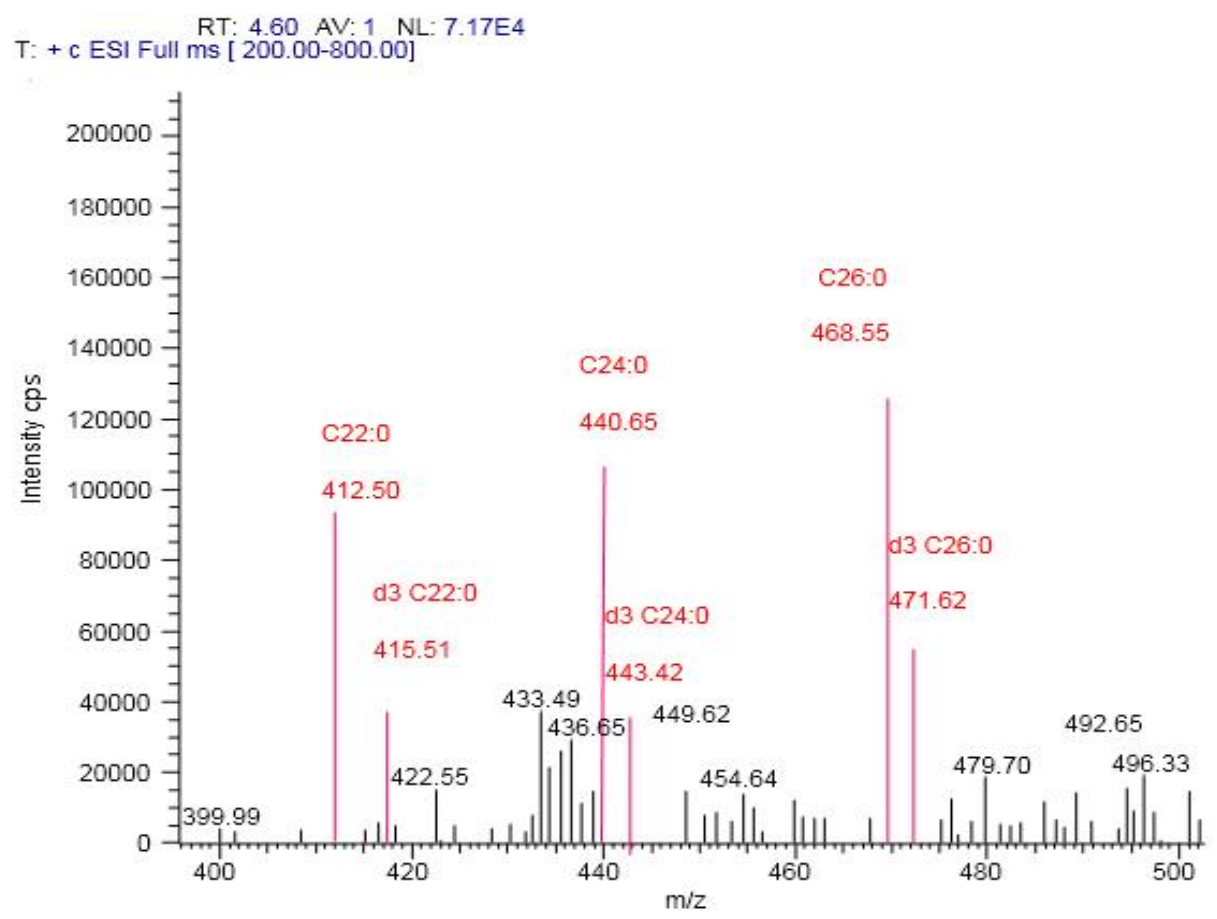

Fig. 3: ESI/MS/MS analysis of the dimethylaminoethyl esters of fatty acids isolated from $5 \mu 1$ plasma samples of the $\mathrm{X}$-ALD disorder patient.

GIIa showed results within the normal range for C20:0, C22:0, C24:0, C26:0, C20:0/C22:0, C24:0/C22:0 and $\mathrm{C} 26: 0 / \mathrm{C} 22: 0$. (GIIb) showed highly significant increase P> 0.001 for C24:0, C26:0, C24:0/C22:0 and C26:0/C22:0 ratios compered to GI (Table 3). Replicate analysis of $5 \mu 1$ samples of normal plasma $(n=5)$ afforded a within-batch coefficient of variation (C.V.) of $1.4 \%$, $1.5 \%$ and $7.5 \%$ for the $\mathrm{C} 20: 0 / \mathrm{C} 22: 0, \mathrm{C} 24: 0 / \mathrm{C} 22: 0$ and the $\mathrm{C} 26: 0 / \mathrm{C} 22: 0$ ratio respectively. The interassay $\mathrm{C} . \mathrm{V}$. $(\mathrm{n}=5)$ were $1.9 \%, 1.8 \%$ and $11.45 \%$ for $\mathrm{C} 20: 0 / \mathrm{C} 22: 0$, C24:0/C22:0 and C26:0/C22:0 ratio respectively. This means that this procedure is reliable and precise.
Comparing the means of the filter paper samples for (GIIa) with (GI) for C22:0, C24:0, C26:0 levels, $\mathrm{C} 24: 0 / \mathrm{C} 22: 0$ and $\mathrm{C} 26: 0 / \mathrm{C} 22: 0$ ratios showed a nonsignificant change. On the other hand comparing the means of (GIIb) with (GI) samples showed a highly significant increase in C24:0, C26:0 levels, C24:0/C22:0 and C26:0/C22:0 ratios respectively (Table 4). Replicate analyses $(n=5)$ for 3-mm spots of a normal blood sample impregnated in filter paper gave a within-batch coefficient of variation of $2.8 \%$ for $\mathrm{C} 24: 0 / \mathrm{C} 22: 0$ and 6.7 $\%$. for $\mathrm{C} 26: 0 / \mathrm{C} 22: 0$ ratios.

Table 3: Plasma VLCFAs for controls and patient samples using deuterated internal standards.

\begin{tabular}{|c|c|c|c|c|c|c|c|}
\hline Groups & $\begin{array}{c}\text { C20:0 } \\
(\mu \mathrm{mol} / \mathrm{L})\end{array}$ & $\begin{array}{c}\text { C22:0 } \\
(\mu \mathrm{mol} / \mathrm{L})\end{array}$ & $\begin{array}{c}\text { C24:0 } \\
(\mu \mathrm{mol} / \mathrm{L})\end{array}$ & $\begin{array}{c}\text { C26:0 } \\
(\mu \mathrm{mol} / \mathrm{L})\end{array}$ & $\begin{array}{c}\text { C20:0 / } \\
\text { C22:0 }\end{array}$ & $\begin{array}{c}\text { C24:0 / } \\
\text { C22:0 }\end{array}$ & $\begin{array}{c}\text { C26:0 / } \\
\text { C22:0 }\end{array}$ \\
\hline $\begin{array}{c}\text { GI } \\
\text { Range } \\
\text { Mean } \pm \\
\text { S.D. } \\
\end{array}$ & $\begin{array}{l}14.5-40.5 \\
26.0 \pm 4.8 \\
\end{array}$ & $\begin{array}{l}31.8-61.6 \\
39.0 \pm 5.6 \\
\end{array}$ & $\begin{array}{r}35.5-56.6 \\
44.1 \pm 5.3 \\
\end{array}$ & $\begin{array}{l}0.95-1.95 \\
1.56 \pm 0.19 \\
\end{array}$ & $\begin{array}{l}0.41-0.79 \\
0.67 \pm 0.11 \\
\end{array}$ & $\begin{array}{r}0.90-1.27 \\
1.14 \pm 0.17 \\
\end{array}$ & $\begin{array}{l}0.026-0.056 \\
0.041 \pm 0.006 \\
\end{array}$ \\
\hline $\begin{array}{l}\text { GIIa } \\
\text { Range } \\
\text { Mean } \pm \\
\text { S.D. } \\
\text { P < } \\
\end{array}$ & $\begin{array}{c}19-30 \\
26.2 \pm 3.3 \\
\text { N.S. }\end{array}$ & $\begin{array}{l}31.9-45.8 \\
39.5 \pm 3.6 \\
\text { N.S. } \\
\end{array}$ & $\begin{array}{c}38-50 \\
44.5 \pm 3.4 \\
\text { N.S. } \\
\end{array}$ & $\begin{array}{c}1.1-1.90 \\
1.59 \pm 0.19 \\
\text { N.S. }\end{array}$ & $\begin{array}{c}0.46-0.8 \\
0.66 \pm 0.08 \\
\text { N.S. }\end{array}$ & $\begin{array}{c}0.9-1.28 \\
1.13 \pm 0.09 \\
\text { N.S. }\end{array}$ & $\begin{array}{c}0.030-0.053 \\
0.040 \pm 0.006 \\
\text { N.S. }\end{array}$ \\
\hline $\begin{array}{c}\text { GIIb } \\
\text { Range } \\
\text { Mean } \pm \\
\text { S.D. } \\
\text { P < }\end{array}$ & $\begin{array}{l}24.8-28.5 \\
26.10 \pm 1.6 \\
\text { N.S }\end{array}$ & $\begin{array}{c}35-50.3 \\
40.12 \pm 6.6 \\
\text { N.S. }\end{array}$ & $\begin{array}{c}70-86.2 \\
76.23 \pm 6.6 \\
0.001\end{array}$ & $\begin{array}{c}3.8-5.5 \\
4.40 \pm 0.69 \\
0.001\end{array}$ & $\begin{array}{c}0.57-0.71 \\
0.66 \pm 0.06 \\
\text { N.S. }\end{array}$ & $\begin{array}{c}1.71-2.03 \\
1.92 \pm 0.14 \\
0.001\end{array}$ & $\begin{array}{c}0.108-0.114 \\
0.110 \pm 0.002 \\
0.001\end{array}$ \\
\hline
\end{tabular}


Table 4: The VLCFAs results for the filter paper samples using deuterated standard.

\begin{tabular}{|c|c|c|c|c|c|}
\hline Groups & $\begin{array}{c}\text { C22:0 } \\
(\mu \mathrm{mol} / \mathrm{L})\end{array}$ & $\begin{array}{c}\text { C24:0 } \\
(\mu \mathrm{mol} / \mathrm{L})\end{array}$ & $\begin{array}{c}\text { C26:0 } \\
(\mu \mathrm{mol} / \mathrm{L})\end{array}$ & C24:0 / C22:0 & C26:0 / C22:0 \\
\hline $\begin{array}{l}\text { GI } \\
\text { Range } \\
\text { Mean } \pm \\
\text { S.D. }\end{array}$ & $\begin{array}{l}30.2-49.5 \\
43.7 \pm 5.9\end{array}$ & $\begin{array}{c}108-147.5 \\
133.2 \pm 15.2\end{array}$ & $\begin{array}{c}3.9-7.3 \\
5.90 \pm 1.39\end{array}$ & $\begin{array}{l}2.44-3.51 \\
3.07 \pm 0.27\end{array}$ & $\begin{array}{l}0.104-0.182 \\
0.134 \pm 0.018\end{array}$ \\
\hline $\begin{array}{l}\text { GII a } \\
\text { Range } \\
\text { Mean } \pm \\
\text { S.D. } \\
\text { P }< \\
\end{array}$ & $\begin{array}{c}37.5-49.5 \\
43.8 \pm 3.8 \\
\text { N.S. }\end{array}$ & $\begin{array}{c}112-147.3 \\
132.7 \pm 10.6 \\
\text { N.S. }\end{array}$ & $\begin{array}{c}4.5-7.1 \\
\\
5.88 \pm 0.86 \\
\text { N.S. }\end{array}$ & $\begin{array}{c}2.51-3.47 \\
3.04 \pm 0.13 \\
\text { N.S. }\end{array}$ & $\begin{array}{c}0.113-0.182 \\
0.134 \pm 0.013 \\
\text { N.S. }\end{array}$ \\
\hline $\begin{array}{l}\text { GIIb } \\
\text { Range } \\
\text { Mean } \pm \\
\text { S.D. } \\
\text { P }< \\
\end{array}$ & $\begin{array}{c}42-55 \\
46.8 \pm 4.91 \\
\text { N.S. }\end{array}$ & $\begin{array}{c}160-172 \\
\\
165.2 \pm 4.54 \\
0.001 \\
\end{array}$ & $\begin{array}{c}11.9-13.2 \\
\\
12.42 \pm 0.51 \\
0.001 \\
\end{array}$ & $\begin{array}{c}3.13-3.81 \\
\\
3.55 \pm 0.26 \\
0.001 \\
\end{array}$ & $\begin{array}{c}0.24-0.283 \\
\\
0.267 \pm 0.02 \\
0.001 \\
\end{array}$ \\
\hline
\end{tabular}

Comparing the means of $\mathrm{C} 22: 0, \mathrm{C} 24: 0$ and $\mathrm{C} 26: 0$ values, C24:0/C22 and C26/C22 ratios of filter paper samples with plasma samples for (GI), (GIIa) and (GIIb) showed significant increase in C22:0 for (GI), and a highly significant increase in the remaining VLCFAs and their ratios (Table 5).

Comparing the means of (GIIa) with (GI) samples without using deuterated internal standards for C20:0, C22:0, C24:0, C26:0 values, C20:0/C22:0, C24:0/C22:0 and $\mathrm{C} 26: 0 / \mathrm{C} 22: 0$ ratios showed a non-significant change for all parameters. On the other hand comparing the means of (GIlb) with (GI) samples showed a highly significant increase for $\mathrm{C} 24: 0, \mathrm{C} 26: 0$ values, C24:0/C22:0 and C26:0 /C22:0 ratios (Table 6).

Comparing the results of plasma samples using undeuterated external standard with the plasma samples using deuterated internal standard showed a highly significant decrease in C20:0, C22:0, C24:0, C26:0, $\mathrm{C} 20: 0 / \mathrm{C} 22: 0, \mathrm{C} 26: 0 / \mathrm{C} 22: 0$ and a non-significant increase for $\mathrm{C} 24: 0 / \mathrm{C} 22: 0$ for $(\mathrm{GI})$ samples. In case of (GIIa) it showed a highly significant decrease for C20:0, C22:0, $\mathrm{C} 24: 0, \mathrm{C} 26: 0, \mathrm{C} 20: 0 / \mathrm{C} 22: 0, \mathrm{C} 26: 0 / \mathrm{C} 22: 0$ and a nonsignificant decrease in $\mathrm{C} 24: 0 / \mathrm{C} 22: 0$. Also the comparison of the VLCFA results of (GIIb) samples showed a highly significant decrease for C20:0, C22:0, C24:0, C26:0, C26:0/C22:0, a significant decrease in C20:0/C22:0 and a highly significant increase in C24:0/C22:0 (Table 7).

Phytanic and pristanic results for the 50 patients group (GII) were within the normal range of the control group (GI). Comparing the mean values of (GII) with (GI) plasma samples showed a non-significant change (Table 8).

Table 5: A comparison between means of VLCFAs results for filter paper samples with plasma samples.

\begin{tabular}{|l|c|c|c|}
\hline \multicolumn{1}{|c|}{ Groups } & $\begin{array}{c}\text { Plasma Samples } \\
(\boldsymbol{\mu m o l} / \mathbf{L})\end{array}$ & $\begin{array}{c}\text { Filter Paper Samples } \\
(\boldsymbol{\mu m o l} / \mathbf{L})\end{array}$ & $\mathbf{P}<$ \\
\hline GI & & & \\
Mean C22:0 & 39 & 43.7 & 0.05 \\
Mean C24:0 & 44.1 & 133.2 & 0.001 \\
Mean C26:0 & 1.56 & 5.9 & 0.001 \\
Mean C24:0/C22:0 & 1.145 & 3.07 & 0.001 \\
Mean C26:0/C22:0 & 0.041 & 0.134 & 0.001 \\
\hline GII a & & & \\
Mean C22:0 & 39.53 & 43.78 & 0.001 \\
Mean C24:0 & 44.5 & 132.7 & 0.001 \\
Mean C26:0 & 1.59 & 5.88 & 0.001 \\
Mean C24:0/C22:0 & 1.13 & 3.035 & 0.001 \\
Mean C26:0/C22:0 & 0.04 & 0.134 & 0.001 \\
\hline GII b & & & \\
Mean C22:0 & 40.12 & 46.8 & 0.01 \\
Mean C24:0 & 76.23 & 165.23 & 0.001 \\
Mean C26:0 & 4.4 & 12.42 & 0.001 \\
Mean C24:0/C22:0 & 1.92 & 3.55 & 0.001 \\
Mean C26:0/C22:0 & 0.11 & 0.267 & 0.001 \\
\hline
\end{tabular}


Table 6: Plasma VLCFAs for controls and patients using undeuterated external standards.

\begin{tabular}{|c|c|c|c|c|c|c|c|}
\hline Groups & $\begin{array}{c}\text { C20:0 } \\
(\mu \mathrm{mol} / \mathrm{L})\end{array}$ & $\begin{array}{c}\text { C22:0 } \\
(\mu \mathrm{mol} / \mathrm{L})\end{array}$ & $\begin{array}{c}\text { C24:0 } \\
(\mu \mathrm{mol} / \mathrm{L})\end{array}$ & $\begin{array}{c}\text { C26:0 } \\
(\mu \mathrm{mol} / \mathrm{L})\end{array}$ & C20:0/C22:0 & C24:0/C22:0 & C26:0/C22:0 \\
\hline $\begin{array}{l}\text { GI } \\
\text { Range } \\
\text { Mean } \pm \\
\text { S.D. }\end{array}$ & $\begin{array}{l}14.0-39.0 \\
24.9 \pm 4.7\end{array}$ & $\begin{array}{l}29.1-54.4 \\
38.0 \pm 5.7\end{array}$ & $\begin{array}{l}34.3-55.3 \\
43.0 \pm 5.4\end{array}$ & $\begin{array}{l}0.75-1.55 \\
1.27 \pm 0.17\end{array}$ & $\begin{array}{l}0.43-0.8 \\
0.66 \pm 0.11\end{array}$ & $\begin{array}{l}0.94-1.26 \\
1.15 \pm 0.18\end{array}$ & $\begin{array}{l}0.024-0.045 \\
0.034 \pm 0.005\end{array}$ \\
\hline $\begin{array}{l}\text { GIIa } \\
\text { Range } \\
\text { Mean } \pm \\
\text { S.D. } \\
\text { P < }\end{array}$ & $\begin{array}{c}16.8-29.0 \\
25.1 \pm 3.4 \\
\text { N.S. }\end{array}$ & $\begin{array}{c}31.0-44.5 \\
38.7 \pm 3.7 \\
\text { N.S. }\end{array}$ & $\begin{array}{c}33.1-50.2 \\
43.3 \pm 4.9 \\
\text { N.S. }\end{array}$ & $\begin{array}{c}0.82-1.52 \\
1.30 \pm 0.17 \\
\text { N.S. }\end{array}$ & $\begin{array}{c}0.46-0.79 \\
0.65 \pm 0.08 \\
\text { N.S. }\end{array}$ & $\begin{array}{c}0.89-1.38 \\
1.12 \pm 0.11 \\
\text { N.S. }\end{array}$ & $\begin{array}{c}0.022-0.042 \\
0.034 \pm 0.005 \\
\text { N.S. }\end{array}$ \\
\hline $\begin{array}{l}\text { GIIb } \\
\text { Range } \\
\text { Mean } \pm \\
\text { S.D. } \\
\text { P < }\end{array}$ & $\begin{array}{c}23.9-27.3 \\
25.0 \pm 1.4 \\
\text { N.S. }\end{array}$ & $\begin{array}{c}34.1-49.2 \\
39.10 \pm 6.5 \\
\text { N.S. }\end{array}$ & $\begin{array}{c}69.1-85.5 \\
75.18 \pm 6.7 \\
0.001\end{array}$ & $\begin{array}{c}3.5-4.9 \\
4.00 \pm 0.58 \\
0.001\end{array}$ & $\begin{array}{c}0.55-0.70 \\
0.65 \pm 0.06 \\
\text { N.S. }\end{array}$ & $\begin{array}{c}1.74-2.05 \\
1.94 \pm 0.14 \\
0.001\end{array}$ & $\begin{array}{c}0.099-0.108 \\
0.103 \pm 0.004 \\
0.001\end{array}$ \\
\hline
\end{tabular}

Table 7: A comparison between results using undeuterated external standards with deuterated internal standards.

\begin{tabular}{|l|c|c|c|}
\hline \multicolumn{1}{|c|}{ Groups } & $\begin{array}{c}\text { Plasma Samples with } \\
\text { Deuterated Internal Standards }\end{array}$ & $\begin{array}{c}\text { Plasma Samples with } \\
\text { undeuterated external Standards }\end{array}$ & P \\
\hline GI & 26 & 24.9 & 0.001 \\
Mean C20:0 & 39 & 38 & 0.001 \\
Mean C22:0 & 44.1 & 43 & 0.001 \\
Mean C24:0 & 1.56 & 1.27 & 0.001 \\
Mean C26:0 & 0.67 & 0.66 & 0.001 \\
Mean C20:0/C22:0 & 1.145 & 1.147 & N.S. \\
Mean C24:0/C22:0 & 0.041 & 0.034 & 0.001 \\
Mean C26:0/C22:0 & 26.2 & 24.1 & 0.001 \\
\hline GIIa & 39.5 & 38.7 & 0.001 \\
Mean C20:0 & 44.5 & 43.3 & 0.01 \\
Mean C22:0 & 1.59 & 1.3 & 0.001 \\
Mean C24:0 & 0.66 & 0.65 & 0.001 \\
Mean C26:0 & 1.13 & 1.12 & N.S. \\
Mean C20:0/C22:0 & 0.04 & 0.034 & 0.001 \\
Mean C24:0/C22:0 & 26.1 & 25 & 0.001 \\
Mean C26:0/C22:0 & 40.12 & 39.1 & 0.001 \\
\hline GIIb & 76.23 & 75.18 & 0.001 \\
Mean C20:0 & 4.4 & 4.0 & 0.01 \\
Mean C22:0 & 0.66 & 0.65 & 0.05 \\
Mean C24:0 & 1.92 & 1.94 & 0.001 \\
Mean C26:0 & 0.11 & 0.103 & 0.001 \\
Mean C20:0/C22:0 & & & \\
Mean C24:0/C22:0 & & & \\
Mean C26:0/C22:0 & & & \\
\hline
\end{tabular}


Table 8: Means of patients and control plasma sample results for phytanic and pristanic acids.

\begin{tabular}{|l|c|c|}
\hline \multicolumn{1}{|c|}{ Groups } & Phytanic & Pristanic \\
\hline GI & & \\
Range & $0.15-10.6$ & $0.13-1.15$ \\
Mean \pm S.D. & $3.457 \pm 2.99$ & $0.527 \pm 0.31$ \\
\hline GII & & \\
Range & $0.2-10.4$ & $0.15-1.13$ \\
Mean \pm S.D. & $3.5 \pm 2.67$ & $0.566 \pm 0.24$ \\
P value < & N.S. & N.S. \\
\hline
\end{tabular}

\section{Discussion}

PDs are a heterogeneous group of inborn error of metabolism that results in impairment of peroxisome function which leads to a neurologic dysfunction of varying extent for most cases ${ }^{[3]}$. X-ALD is the most common PD with impaired $\beta$-oxidation of saturated VLCFAs ${ }^{[6]}$. There are at least six distinct types of XALD (Childhood cerebral, Adolescence, Adult cerebral, Adrenomyeloneuropathy, Addison, Asymptomatic and Phenotypes in female carriers). First sign is onset of adrenal insufficiency and progressive neurological dysfunction. Frequent initial symptoms include emotional liability, hyperactive behavior, school failure, impaired auditory discrimination, central deafness and difficulties in vision. After the onset of symptoms the disease course is rapidly progressive, leading to an apparently vegetative state within 2 to 4 years and to death at varying intervals there after ${ }^{[20]}$. The main aim of this study is to establish a rapid procedure for the diagnosis of (PDs) by the quantification of VLCFAs in plasma and filter paper to decrease the cost of expensive collection and shipping of plasma samples. Also comparison between using deuterated and undeuterated standards to decrease the cost of deuterated standards.

In this study 50 patients were suspected to have peroxisomal disorders, six cases were clinically diagnosed as having X-ALD disorder. This agrees with Kemp's study mentioning that X-ALD is the most common type of peroxisomal disorders which occurs in all regions of the world ${ }^{[21]}$. Consanguineous marriage is frequent among Egyptians; it ranges from $29.5 \%$ to $75 \%$ ${ }^{[22]}$. In biochemical diagnosis of peroxisomal disorders by GC/MS study ${ }^{[23]}$, the parental consanguinity was $61 \%$, while the percentage was $75 \%$ among the positive cases which is coincidence with our study, where positive history of parental consanguinity was present in $46 \%$ cases and the positive consanguinity present among the X-ALD diagnosed cases was $84 \%$.

The age range for this study was between 2 and 10 years. The age range of the $6 \mathrm{X}$-ALD diagnosed cases is from ( 2.8 to 6.7 years), they are all of the childhood cerebral type, which is the most severe phenotype. The age of the study group is matching with previous studies ${ }^{[23,24]}$. The study group included 45 males $(90 \%)$ and 5 females
(10\%). All the diagnosed X-ALD cases were males. This coincides with the mode of inheritance of this disorder since it is caused by mutations in the ABCD1 gene located on X-chromosome and accordingly all diagnosed cases were males ${ }^{[24]}$. Previous studies also agreed with these results concerning the sex of the diagnosed cases ${ }^{[23,}$ 24].

Serum ALT and $\gamma$ GT levels in all patients were higher than controls confirming that the patients are suffering from liver dysfunction, which is one of the important sign for peroxisomal disorders. Comparing the means of (GIIa) and (GIlb) samples with the means of (GI) samples showed very high significant increase for both ALT and $\gamma \mathrm{GT}$, This Indicating that these patients are suffering from abnormalities in liver functions, which is a marker for peroxisomal disorders specially ZSDs which is matching with Poll-The \& Gartner, who declared that liver disease is common in ZSDs patients ${ }^{[6]}$. Also comparing the means of (GIIb) samples with the means of (GIIa) samples showed a highly significant increase, which means that these 6 patients are suffering from hepatic dysfunction due to the accumulation of VLCFAs in their liver tissues, which also agrees with Engelen, who mentioned that a defect in ALDP results in elevated levels of VLCFA in plasma and tissues ${ }^{[25]}$.

Plasma VLCFA analysis is the best initial biomarker for the diagnosis of X-ALD. Four parameters (C24:0, C26:0, $\mathrm{C} 42: 0 / \mathrm{C} 22: 0$ and $\mathrm{C} 26: / \mathrm{C} 22$ ) should be analyzed ${ }^{[26]}$. In this study ESI-MS/MS analysis of the dimethylaminoethyl ester used for quantification of $\mathrm{C} 20: 0, \quad \mathrm{C} 22: 0, \quad \mathrm{C} 24: 0$ values and C20:0/C22:0, $\mathrm{C} 24: 0 / \mathrm{C} 22: 0$ \& $\mathrm{C} 26: 0 / \mathrm{C} 22: 0$ ratios. This method is faster than using gas chromatography (GC) ${ }^{[27,28]}$ or gas chromatography-mass spectrometry (GC-MS) ${ }^{[29]}$ which takes 1-2 days. The amount of plasma used for the analysis was reduced to $5 \mu \mathrm{l}$ from the $200 \mu \mathrm{l}$ needed for the GC assay or $100 \mu \mathrm{l}$ needed for GC-MS assay. This method is saving time compare to the GC-Ms method since sample preparation time is around 2 hours and ESIMS/MS instrument analysis time is $3.5 \mathrm{~min} / \mathrm{sample}$. Due to the lack of appropriate standards, quantification of VLCFA is frequently based only on the calculation of significant ratios such as C24:0/C22:0 and C26:0/C22:0. The ion scan for dimethylaminoethyl ester of C26:0 gave 
protonated molecular ion at $\mathrm{m} / \mathrm{z} 468$ and $\mathrm{m} / \mathrm{z}$ of 423 (loss of $\mathrm{m} / \mathrm{z} 45$ ), which is coincident with Johnson's results ${ }^{[18]}$.

The measurements of 25 control samples for VLCFAs were within the control measurements of Johnson's results ${ }^{[18]}$. It is noticed that the MRM mode didn't detect the C26:0 ions in the normal sample due to its low concentration, while in the patient sample both C24:0 and $\mathrm{C} 26: 0$ have been detected due to the accumulation of the VLCFA because of the $\beta$-Oxidation defect (Fig 4). For this patient $\mathrm{C} 24: 0 / \mathrm{C} 22: 0$ and $\mathrm{C} 26: 0 / \mathrm{C} 22: 0$ were higher than normal and the patient were diagnosed as XALD disorder. These results were coincident with Johnson's results ${ }^{[18]}$.

Comparing the VLCFAs means of (GIIa) with (GI) plasma samples was not significant. On the other hand comparing the means of (GIIb) with (GI) showed a high significant increase for C24:0, C26:0 values, C24/C22 and $\mathrm{C} 26 / \mathrm{C} 22$ ratios, which prove the clinical diagnosis for the 6 patients as a result of the impaired VLCFA degradation due to the deficient import of VLCFA into peroxisome, the synthesis of VLCFA is enhanced in XALD and their accumulation occurs in different tissues in the body and their levels increases in plasma ${ }^{[7]}$. The intraday and interassay analysis proves that the method is precise and reliable.

The VLCFA were quantified also in 3-mm blood spot samples by the same procedure used for the plasma samples. Comparing the mean results of VLCFAs and their ratios for (GIIa) with that of (GI) showed nonsignificant changes. These results reflect that these patients are not suffering from VLCFA disorders. Comparing the means of (GIIb) with (GI) revealed a very high significant increase for C22:0, C24:0, C26:0 values, C24:0/C22:0 and C26:0/C22:0 ratios (Table 4), which indicate that they are suffering from VLCFA accumulation. These results were in agreement with Johnson's results ${ }^{(18)}$. The C24:0/C22:0 and C26:0/C22:0 ratios for controls and the $6 \mathrm{X}$-ALD patients are in coincident with Jakobs' results ${ }^{[30]}$. The intraday analysis proves that the method is precise and reliable.

Comparing the mean results for the filter paper samples with plasma samples showed a very high significant increase. This increase is due to two reasons. The $1^{\text {st }}$ one is the presence of VLCFA in the wax esters found in Guthrie cards which vary with fiber source. Also bacteria and fungi could contaminate the Guthrie card by VLCFA. The $2^{\text {nd }}$ reason is the presence of VLCFA in the red blood cells present in the blood spot on the Guthrie card storage also could affect the results of VLCFA ${ }^{[18]}$.

Because of the high expenses of the deuterated internal standard for the VLCFA, we tried to decrease the cost by measuring the VLCFA using ES-MS/MS method and unlabeled external standards for the same 50 patients and 25 controls plasma samples, without using the deuterated internal standard. Comparing the means of $\mathrm{C} 20: 0$, C22:0, C24:0, C26:0 values, C20:0/C22:0, C24:0/C22:0 and C26: 0 /C22:0 ratios for (GIIa) with (GI) showed a non-significant change for all VLCFAs and it was the normal range (Tables 6), which means that (GIIa) doesn't have VLCFA disorders and may suffer from another peroxisomal disorder like (PBD). According to our knowledge this is the $1^{\text {st }}$ study to measure VLCFAs using ESI/MS/MS without using deuterated internal standard.

Comparing the VLCFAs means for (GIIb) with (GI) plasma samples without using deuterated internal standard showed a very high significant increase for C24:0, C26:0 value, C24:0/C22:0 and C26:0/C22:0 ratios (Table 7). These results prove the X-ALD diagnosis for these 6 patients. Comparing the results for plasma samples without using deuterated internal standards with the plasma samples results using deuterated internal standards showed a high significant decrease for C20:0, C22:0, C24:0, C26:0, C20:0/C22:0, C26:0/C22:0 and a non-significant increase for C24:0/C22:0 for (GI). (GIIa) results showed a high significant decrease for C20:0, C22:0, C24:0, C26:0, C20:0/C22:0, C26:0/C22:0 and a non-significant decrease for $\mathrm{C} 24: 0 / \mathrm{C} 22: 0$. Also the comparison of the VLCFA (GIIb) results showed a high significant decrease for C20:0, C22:0, C24:0, C26:0, C26:0/C22:0, a significant decrease for C20:0/C22:0 and high significant increase for C24:0/C22:0 (Table 7). This result reflects that using the internal deuterated standards is recommended for making correction for the concentration loss.

Measuring phytanic acid (C20:0 branched) and pristanic acid (C19:0 branched) by combining ESI/MS/MS analysis with HPLC separation for trace analysis of branched fatty acids in plasma ${ }^{[19]}$ is not faster than some GC-MS methods and an LC/API-MS method ${ }^{[31]}$. The sample preparation time was $2 \mathrm{~h}$ plus chromatographic separation cycle time of $30 \mathrm{~min}$, and the plasma needed was $10 \mu \mathrm{l}$ compared with $100-200 \mu \mathrm{l}$ for GC/MS which is an important consideration in pediatric testing. All the 50 patient samples (GII) were within the normal ranges of the control samples (GI) for both phytanic and pristanic acids. Comparing the means of (GII) with that of (GI) showed a non-significant change for both phytanic and pristanic acids (Table 8), which prove that these patients don't have Refsum's Disease's, Rhizomelic Chondrodysplasia Punctata (elevated phytanic acid) or peroxisomal 3-oxoacyl-CoA thiolase deficiency's (elevated pristanic acid). Our results for normal plasma phytanic were coincident with Ten Brink's results ${ }^{32]}$.

In Conclusion: The results of plasma and filter paper samples proved that using ESI-MS/MS method for the determination of VLCFA has good potential to be used as an effective, precise, reliable and rapid screening procedure for many peroxisomal disorders in plasma samples and possibly for dried blood spots by detecting abnormal C24:0/C22:0 and C26:0/C22:0 ratio. Sample preparation time is less than $2 \mathrm{~h}$ and ESI-MS/MS instrument analysis time is $3.5 \mathrm{~min} / \mathrm{sample}$. The role for blood spots "to replace the expensive collection and shipping of plasma samples". The ESI-MS/MS method can also be used to monitor peroxisomal disorder patients on dietary therapy. Measuring VLCFA without labeled 
internal standard decreases the cost, but it is not recommend because of concentration correction effect of the labeled internal standard. Using HPLC with ESI/MS/MS for measuring phytanic and pristanic acids is a sensitive method, but needs more samples volume and more time for refining.

\section{References}

1) Oglesbee, D. (2005). An overview of peroxisomal biogenesis disorders. Mol. Genet. Metab., 84: 299301.

2) Fidalieo, M. (2010). Peroxisomes and peroxisomal disorders: The main facts. Experimental and Toxicologic Pathology, 62: 615-625.

3) Wanders, R. J. (2004). Metabolic and molecular basis of peroxisomal disorders: a review, Am. J. Med. Genet. A 126A: 355-375.

4) Jansen, G. A., van den Brink, D. M., Ofman, R., Draghici, O., Dacremont G. and Wanders, R. J. (2001). Identification of pristanal dehydrogenase activity in peroxisomes: conclusive evidence that the complete phytanic acid alpha-oxidation pathway is localized in peroxisomes. Biochem. Biophys. Res. Commun. 283(3): 674-679.

5) Wanders, R. J. and Waterham, H. R. (2005). Peroxisomal disorders I: biochemistry and genetics of peroxisome biogenesis disorders. Clin. Genet, 67(2): 107-33.

6) Poll-The, B. T. and Gartner, J. (2012). Clinical diagnosis, biochemical findings and MRI spectrum of peroxisomal disorders. Biochem. Biophys. Acta., 1822: 1421-1429.

7) Kemp, S. and Wanders, R. J. (2007). X-linked adrenoleukodystrophy: very long-chain fatty acid metabolism, ABC half-transporters and the complicated route to treatment. Mol. Genet. Metab., 90(3): 268-276.

8) Clayton, P. T. (2001). Clinical consequences of defects in peroxisomal beta-oxidation. Biochem. Soc. Trans. 29: 298-305.

9) Loes, D.L., Hite, S., Moser, H., Stillman, A. E., Shapiro, E., Lockman, L., Latchaw, W. and Krivit, (1994). Adrenoleukodystrophy: a scoring method for brain MR observations, Am. J. Neuroradiol, 15: 1761-1766.

10) Van der Knaap, M. S. and Valk, J. (1991). The MR spectrum of peroxisomal disorders. Neuroradiology, 33: 30-37.

11) Temtamy, S. A., El-Sawy, M. A., Aboul-Ezz, E. H. A., El-Din, M. K., Fatteen, E. M., Meguid, N. A., Samy, E., Dacremont, S. C., Leroy, H. J. G. and Bassyouni, H. (1993). Screening for peroxisomal and sialic acid disorders in progressive neurologic disorders among Egyptian children. Applied Endocrinology in Egypt, 11(2); 17.

12) Moser, H. W., Roymond, G.V., Lu S-E, muenz, L.R., Moser, A. B., Xu, J., Jones, R. O., Loes, D. J., Melhem, E. R., Dubey, P., Bezman, L., Brereton, N. H. and Odone, A. (2005). Follow up of 89 asymptomatic patients with adrenoleucodys- trophy treated with Lorenzo's Oil. Arch Neurol, 62: 1073-80.

13) Singh, I., Pahan, K. and Khan, M. (1998). Lovastatin and sodium phenylacetate normalize the levels of very long chain fatty acids in skin fibroblasts of X-adrenoleukodystrophy. FEBS Lett, 426 (3): 342-6.

14) Matern, D., Oglesbee, D. and Tortorelli, S. (2014). New born screening for lysosomal storage disorders and other neuronopathic conditions. Dev. Disabil. Res. Rev., 17(3): 247-253.

15) Vogel, B.H., Brandley, S. E., Adams, D. J., D’Aco, k., Erbe, R. W., Fong, C., Iglesias, A., Kronn, D., Levy, P., Morrissey, M., Orsini, J., Parton, P., Pellegrino, J., Saavedra-Matiz, C. A., Shur, N., Wasserstein, M., Raymond, G. V. and Caggana, M. (2015). Newborn screening for X-linked adrenleukodystrophy in New York State: Diagnostic protocol, surveillance protocol and treatment guidelines. Mole. Gen. Met. 114(14): 599-603.

16) Bergmeyer, H. U. and Horder, M. (1980). IFCC method of alanine aminotransferase. J. Clin. Chem. Clin. Biochem. 18: 521-534.

17) Szasz, G. (1969). Reaction-rate method for $\gamma$ glutamyltransferase activity in serum. Clin Chem. 22: 124-136.

18) Johnson, D. W. (2000). A rapid screening procedure for the diagnosis of peroxisomal disorders: quantification of very long chain fatty acids as dimethyaminoethyl esters in plasma and blood spots by electrospray tandem mass spectrometry. J. Inherit. Metab. Dis., 23: 475-486.

19) Johnson, D. W., Trinh, M. U. and Oe, T. (2003). Measurement of pristanic, phytanic and very long chain fatty acids by liquid chromatography electrospray tandem mass spectrometry for the diagnosis of peroxisomal disorders. J. Chromatogr. B., 798: 159-162.

20) Berger, J. and Gartner, J. (2006). X-linked adrenoleukodystrophy: clinical, biochemical and pathogenic aspects. Biochim. Biophys. Acta. 1763: 1721-1732.

21) Kemp, S., Pujol, A., Waterham, H. R., van Geel, B. M., Boehm, C. D., Raymond, G. V., Cutting, G. R., Wanders, R. J. and Moser, H. W. (2001). ABCD1 mutations and the X-linked adrenoleukodystrophy mutation database: role in diagnosis and clinical correlations. Hum. Mutat., 18: 499-515.

22) Afifi, H. H., El-Ruby, M. O., El-Bassyouni, H. T., Ismail, S. I., Aglan, M. S., El-Harouni, A. A., Mazen, I. M., Zaki, M. S., Bassiouni, R. I., Hosny, L. A., El-Kamah, G. Y., El-Kotoury, A. I., Ashour, A. M., Abdel-Salam, G. M., El-Gammal, M. A., Hamed, K., Kamal, R. M., El-Nekhely, I. and Temtamy, S. A. (2010). The most encountered groups of genetic disorders in Giza Governorate, Bratisl Lek Listy, 111: 62-69. 
23) Fateen, E., Gouda, A. and Ibrahim, M. (2013). Biochemical Diagnosis of Peroxisomal Disorders by GC/MS: four Egyptian Patients with X-linked Adrenoleukodystrophy. The Egyptian Journal of Hospital Medicine 53:960-966.

24) Mosser, J., Douar, A. M., Sarde, C. O., Kioschis, P., Feil, R., Moser, H., Poustka, A. M., Mandel, J. L. and Aubourg, P. (1993). Putative X-linked adrenoleukodystrophy gene sharres unexpected homology with $\mathrm{ABC}$ transporters. Nature 361: 726730.

25) Engelen, M., Kemp, S., de Visser, M., van Geel, B. M., Wanders, R. J. A., Aubourg, P. and PollThe B. (2012), X-linked adrenoleukodystrophy (XALD): clinical presentation and guidelines for diagnosis, follow-up and management. Orphanet Journal of Rare Diseases, 7(1): 51.

26) Kemp, S., Berger, J. and Aubourg, P. (2012). Xlinked adrenoleukodystrophy: Clinical, metabolic, genetics and pathophysiological aspects. Biochemica et Biophysica Acta, 1822: 1465-1474.

27) Moser, H.W. and Moser, A. B. (1991). Measurement of saturated very long chain fatty acids in plasma. In techniques in Diagnostic Human Biochemical Genetics. F. A. Hommes, editor. Wiley-Liss, New York. 177-191.
28) Paik, M. J., Lee, K. O. and Shin, H. S. (1999). Determination of very long chain fatty acids in serum gas chromatography-nitrogen-phosphorus detection following cyan methylation. J. Chromatogr. B. Biomed Sci Appl. 721: 3-11.

29) Stellaard, F., ten Brink, H. J., Kok, R. H., van den Heuvel, L. and Jakobs, C. (1990). Stable isotopic dilution analysis of very long chain fatty acids in plasma. Urine and amniotic fluid electron capture negative ion mass fragmentography. Clin Chim Acta 192: 133-144.

30) Jakobs, C., van den Heuvel, C. M. M., Stellaard, F., Largilliere, C., Skovby, F. and Christensen, E. (1993). Diagnosis of Zellweger syndrome by analysis of very long chain fatty acids in stored blood spots collected at neonatal screening. J. Inherit. Metab. Dis. 16:63-66.

31) Schrade, S., Goggerle, M. and Korall, H. (2000). Screening for peroxisomal disorders: Determination of VLCFA and phytanic acid by LC/APCI-MS. J. Inher. Metab. Dis. 23(S1): 242.

32) Ten Brink, H.J., Schor, D. S., Kok, R.M., PollThe, B. T., Wanders, R. J. A. and Jakobs, C. (1992). Phytanic acid $\alpha$-oxidation: accumulation of 2hydroxyphytanic acid and absence of 2-oxophytanic acid in plasma from patients with peroxisomal disorders. J Lipid Res, 33: 1449-1457. 